Rev. Bras. Saúde Prod. Anim., Salvador, v.16, n.3, p.723-735 jul./set.., $2015 \quad \underline{\text { http://www.rbspa.ufba.br }}$

\title{
Características da carcaça e componentes não integrantes da carcaça de caprinos Canindé suplementados na caatinga ${ }^{1}$
}

\author{
Characteristics of carcass and non-carcass components of Canindé goats under \\ supplementation and grazing in the caatinga
}

SOUZA, Cicília Maria Silva de ${ }^{2 *}$; MEDEIROS, Ariosvaldo Nunes de ${ }^{3}$; COSTA, Roberto Germano ${ }^{4}$; PEREIRA, Elzania Sales ${ }^{5}$; AZEVEDO, Paulo Sérgio de ${ }^{3}$; LIMA JÚNIOR, Valdi de ${ }^{6}$; ROCHA, Luciana Porangaba da ${ }^{7}$; SOUZA, Anaiane Pereira ${ }^{8}$

\footnotetext{
${ }^{1}$ Pesquisa financiada pelo Banco do nordeste - BNB/ETENE/FUNDECI/CAPES.

${ }^{2}$ Instituição Federal de Educação, Ciência e Tecnologia do Rio Grande do Norte, Apodi, Rio Grande do Norte, Brasil.

${ }^{3}$ Universidade Federal da Paraíba, Centro de Ciências Agrárias, Departamento de Zootecnia, Areia, Paraíba, Brasil.

${ }^{4}$ Universidade Federal da Paraíba, Departamento de Agropecuária, Bananeiras, Paraíba, Brasil.

${ }^{5}$ Universidade Federal do Ceará, Departamento de Zootecnia, Fortaleza, Ceará, Brasil.

${ }^{6}$ Universidade Federal do Rio Grande do Norte, Departamento de Zootecnia, Natal, Rio Grande do Norte, Brasil.

${ }^{7}$ Universidade Federal da Paraíba, Centro de Ciências Agrárias, Programa de Pós-Graduação em Zootecnia, Areia, Paraíba, Brasil.

${ }^{8}$ Universidade Estadual Paulista, Programa de Pós-Graduação em Zootecnia, Jaboticabal, São Paulo, Brasil.

*Endereço para correspondência: ciciliazoot@gmail.com
}

RESUMO

Objetivou-se avaliar o efeito da suplementação concentrada sobre o ganho de peso, as características quantitativas da carcaça e dos não constituintes da carcaça de caprinos castrados da raça Canindé em sistema de pastejo na caatinga. 40 caprinos com peso corporal (PC) inicial médio de $15,76 \pm 0,96 \mathrm{~kg}$ foram distribuídos nos níveis de zero; 0,$5 ; 1$ e $1,5 \%$ de suplementação concentrada (\% PC), sendo abatidos quando os animais que recebiam $1,5 \%$ de suplementação atingiram peso médio de $23,10 \pm 1,74 \mathrm{~kg}$. Utilizou-se delineamento inteiramente casualizado com quatro níveis de suplementação e dez repetições. $O$ ganho de peso, rendimento de carcaça, rendimento dos cortes e peso dos constituintes não carcaça (pele, cabeça, sangue, fígado, rins, trato respiratório, trato gastrointestinal), bem como o peso da gordura total, foram influenciados positivamente pelos níveis de suplementação. Os níveis de suplementação um e 1,5\% do PC são favoráveis ao desempenho, às características de carcaça e ao desenvolvimento de órgãos em caprinos da raça Canindé em pastejo na caatinga.

Palavras-chave: cortes comerciais, órgãos, raça nativa, rendimento de carcaça, suplementação

\section{SUMMARY}

The aim of this study was to evaluate the effect of concentrate supplementation on weight gain, the quantitative characteristics of carcass and non-carcass components of the castrated goat carcass Canindé breed grazing system in the native pasture caatinga. 40 goats with an average body (BW) initial weight of $15.76 \pm$ $0.96 \mathrm{~kg}$ were distributed in a completely randomized design in levels of $0 ; 0.5 ; 1$ and $1.5 \%$ of supplementation ( $\% \mathrm{BW})$ and were slaughtered when the animals from the $1.5 \%$ of supplementation level reached $23.10 \pm 1.74 \mathrm{~kg}$. Performance, carcass yield, yield of cuts and weight of non-carcass components (skin, head, blood, liver, kidneys, respiratory tract, gastrointestinal tract) as well as total fat weightwere positively influenced by supplementation levels. The supplementation levels of 1 and $1.5 \%$ of body weight are favorable to performance and quantitative characteristics of Canindé goat kids grazing in the native pasture caatinga.

Keywords: carcass yield, commercial cuts, native breed, organs, supplement 
Rev. Bras. Saúde Prod. Anim., Salvador, v.16, n.3, p.723-735 jul./set.., $2015 \quad \underline{\text { http://www.rbspa.ufba.br }}$

\section{INTRODUÇÃO}

O sistema de exploração predominante da caprinocultura no nordeste do Brasil é o extensivo ou o semi-intensivo, com dependência da vegetação de caatinga e da utilização de animais. Os caprinos nativos, na região, são utilizados para produção de leite e carne, sendo a raça Canindé uma dentre as raças nativas criadas (SOUZA et al., 2014).

O desempenho dos animais é influenciado por fatores como o consumo e digestibilidade dos alimentos, assim, o uso de suplementação concentrada na dieta de caprinos em condições de pastejo tem sido empregado para melhorar seu desempenho, de maneira que reduza o tempo de abate, para melhor eficiência de produção do sistema de forma geral.

A comercialização de caprinos no nordeste do Brasil ocorre, tradicionalmente, com base no peso dos animais vivos, os quais são destinados ao abate apresentando idade média de um ano, pesando em torno de $25 \mathrm{~kg}$ e carcaças com peso médio de 12 a $13 \mathrm{~kg}$. Além disso, Silva et al. (2014) afirmam que a qualidade da carne caprina da região ainda está aquém da real necessidade, pois esta é proveniente de carcaças de má conformação ou mal desenvolvimento da massa muscular, apresentando menor rendimento de carcaça e quantidade de produto aproveitável. Sendo assim, para a produção caprina ser técnica e viável, é necessário proporcionar, aos animais, condições para máximo desempenho por meio do fornecimento de alimentação adequada, para alcançar peso ideal de abate e valorização da carcaça, de forma a atender às exigências do mercado consumidor.

Lisboa et al. (2010), citam que os caprinos são uma espécie que apresenta menor intervalo entre o nascimento e o abate, sendo sua carne apreciada, com possibilidade de valorização superior às demais carnes comerciais de ruminantes.

A avaliação da carcaça é considerada uma análise de parâmetros relacionados com medidas de desempenho a partir do consumo, ganho de peso, conversão alimentar e rendimento de carcaça (CARVALHO JUNIOR et al., 2009). No entanto, além desta, como principal unidade de comercialização, há outras partes comestíveis do corpo do animal denominadas de componentes não integrantes da carcaça (coração, rins e outros órgãos), apresentando uma fonte adicional de renda para os produtores (SILVA SOBRINHO \& SILVA, 2000).

Objetivou-se, com esse estudo, avaliar o efeito da suplementação concentrada sobre o ganho de peso, as características quantitativas e os componentes não integrantes da carcaça de caprinos Canindé, criados em sistema de pastejo na caatinga.

\section{MATERIAL E MÉTODOS}

A pesquisa foi conduzida na Estação experimental de pequenos ruminantes, pertencente ao Centro de ciências agrárias da Universidade Federal da Paraíba - CCA/UFPB, localizada no município de São João do Cariri - PB. Os valores médios de precipitação, temperatura máxima, mínima e umidade relativa do ar foram $7,71 \mathrm{~mm} ; 31,9^{\circ} \mathrm{C}$; $17,83^{\circ} \mathrm{C}$ e $74,9 \%$, respectivamente (Bacia Escola - CTRN/UFCG).

Foram utilizados 40 cabritos Canindé, machos, castrados, com peso corporal (PC) médio inicial de 15,76 $\pm 0,96 \mathrm{~kg}$ e idade média de três meses, distribuídos aleatoriamente em um dos quatro níveis de suplementação com concentrado $(0$; 0,$5 ; 1,0$ e $1,5 \%$ PC), sendo 10 cabritos 
Rev. Bras. Saúde Prod. Anim., Salvador, v.16, n.3, p.723-735 jul./set.., $2015 \quad \underline{\text { http://www.rbspa.ufba.br }}$ ISSN 15199940

por nível. Os animais entraram no experimento na mesma época e foram vermifugados em intervalos de três meses.

Os cabritos tiveram acesso diário à pastagem nativa das $6 \mathrm{~h}$ às $16 \mathrm{~h}$, momento em que eram recolhidos para um aprisco provido de baias individuais de $2,0 \times 1,0 \mathrm{~m}$ com piso de chão batido provido de comedouro e desprovido de cobertura, para receberem a suplementação. Os animais tiveram acesso livre à água.

A área experimental era constituída por dois piquetes de aproximadamente 8 ha cada. $\mathrm{O}$ percentual de ocorrência e a disponibilidade dos componentes botânicos analisados na área de estudo foram demonstrados pela predominância do capim "panasco" (Aristida setifolia.
H.B.K.) com 78,20\%, seguida pelo "pereiro" (Aspidosperma piryfolium) com $10,62 \%$ e "caatingueira" (Caesalpinia pyramidalis) com $12,23 \%$, a partir do método dos transectos e do peso bruto (De VRIES, 1958). A disponibilidade de forragem em que foram incluídos os componentes botânicos e serrapilheira variou ao longo do ano, com média de matéria natural de $1674,5 \mathrm{~kg} / \mathrm{ha}$. Os teores de matéria seca e proteína bruta do material disponível para consumo dos animais foi de 87,17 e 4,33\%, respectivamente.

A suplementação alimentar foi composta por uma ração concentrada (Tabela 1), balanceada conforme recomendações do NRC (2007), para ganho de $150 \mathrm{~g} /$ dia para os animais de maior nível de suplementação.

Tabela 1. Ingredientes e composição química do concentrado experimental

\begin{tabular}{|c|c|c|c|c|c|c|c|}
\hline \multirow[b]{2}{*}{$\begin{array}{l}\text { Composição } \\
\text { química }^{1}\end{array}$} & \multicolumn{7}{|c|}{ Ingredientes } \\
\hline & $\begin{array}{c}\text { Farelo de } \\
\text { milho }^{2}\end{array}$ & $\begin{array}{c}\text { Farelo } \\
\text { de soja }\end{array}$ & $\begin{array}{c}\text { Farelo } \\
\text { de trigo }\end{array}$ & $\begin{array}{l}\text { Farelo de } \\
\text { algodão }\end{array}$ & Calcário & $\begin{array}{c}\text { Suplemento } \\
\text { mineral }^{3}\end{array}$ & Concentrado \\
\hline Matéria seca & 863,0 & 853,3 & 833,2 & 854,0 & 999,5 & 970,4 & 864,1 \\
\hline Matéria orgânica & 958,3 & 940,2 & 939,9 & 946,6 & 6,70 & 19,6 & 870,4 \\
\hline Matéria mineral & 41,7 & 59,8 & 60,1 & 53,4 & 994,3 & 980,4 & 121,6 \\
\hline Proteína bruta & 111,5 & 467,4 & 157,8 & 325,0 & - & - & 215,5 \\
\hline $\mathrm{FDN}^{4}$ & 276,7 & 160,0 & 493,2 & 523,3 & - & - & 325,3 \\
\hline FDA $^{5}$ & 103,8 & 110,7 & 278,9 & 307,9 & - & - & 111,1 \\
\hline Extrato etéreo & 114,9 & 22,4 & 24,5 & 20,6 & - & - & 84,9 \\
\hline NIDA $^{6}$ & 8,8 & 20,0 & 5,2 & 8,2 & - & - & 19,6 \\
\hline DIVMS $^{7}$ & - & - & - & - & - & - & 744,3 \\
\hline CT & 168,1 & 449,3 & 142,6 & 299,0 & - & - & 322,0 \\
\hline $\mathrm{EM}^{9}$ & 2,25 & 2,58 & 2,36 & 2,38 & - & - & 2,41 \\
\hline \multicolumn{8}{|c|}{ Proporção dos ingredientes } \\
\hline Concentrado & 580 & 270 & 50 & 50 & 10 & 40 & - \\
\hline
\end{tabular}

Para o controle do desenvolvimento ponderal e ajuste do fornecimento do concentrado, os animais foram pesados semanalmente em jejum.
A estimativa do consumo da matéria seca (CMS) a pasto foi realizada a partir da estimativa da produção fecal e da digestibilidade da MS da extrusa de quatro caprinos machos, castrados, da 
Rev. Bras. Saúde Prod. Anim., Salvador, v.16, n.3, p.723-735 jul./set.., $2015 \quad \underline{\text { http://www.rbspa.ufba.br }}$

raça Canindé, com cânulas permanentes de rúmen, com $\mathrm{PC}$ de $22 \pm 2,23 \mathrm{~kg}$ e, aproximadamente, 12 meses de idade, distribuídos em um quadrado latino simples.

A colheita da extrusa ruminal foi realizada segundo metodologia descrita por Santos et al. (2008) durante quatro dias consecutivos, em turnos alternados (manhã e tarde). O material presente no rúmen do animal foi retirado por completo e, em seguida, este foi solto no piquete para pastejar durante um período de 60 minutos; ao retornar para o centro de manejo, a extrusa ruminal selecionada no pasto pelo animal foi colhida e armazenada em freezer para formação de amostras compostas por animal e por período e, em seguida, era devolvida ao rúmen. Nesses mesmos períodos as fezes foram pesadas $\mathrm{e}$ amostradas para estimar a produção fecal através do indicador interno fibra em detergente neutro indigestível (FDNi). As amostras compostas da extrusa ruminal e das fezes por animal e período foram acondicionadas em sacos plásticos e congeladas.

As amostras de extrusa e fezes foram pesadas e secas em estufa de ventilação forçada a $55^{\circ} \mathrm{C}$, por $72 \mathrm{~h}$, e, juntamente com os ingredientes do concentrado, foram trituradas e submetidas às análises de matéria seca (MS), matéria mineral (MM), proteína bruta (PB) e extrato etéreo (EE), em aparelho tipo Soxhlet, segundo o método descrito pela AOAC (1990). A Fibra em detergente neutro (FDN), fibra em detergente ácido (FDA) e nitrogênio insolúvel em detergente ácido (NIDA) foram determinados segundo metodologia descrita por Van Soest (1985).

A composição química da extrusa foi de $156,7 \mathrm{~g} / \mathrm{kg}$ deMS; $151,1 \mathrm{~g} / \mathrm{kg}$ de MM; $89,3 \mathrm{~g} / \mathrm{kg}$ de $\mathrm{PB} ; 713 \mathrm{~g} / \mathrm{kg}$ de $\mathrm{FDN}$; $510 \mathrm{~g} / \mathrm{kg}$ de FDA e $1,3 \mathrm{Mcal} / \mathrm{kg}$ de energia metabolizável, considerando $82 \%$ da energia digestível.

A digestibilidade in vitro na materia seca (DIVMS) da extrusa foi realizada conforme a metodologia proposta por Tilley \& Terry (1963). O teor de carboidratos totais foi obtido através da equação: $\%$ CHOT $=100-(\% \mathrm{~PB}+$ $\%$ EE $+\%$ Cinzas), proposta por Sniffen et al. (1992). A fibra em detergente neutro indigestível (FDNi) foi determinada pela incubação das amostras no rúmen de caprinos por meio de fístula ruminal, por um período de 240 horas (CASALI et al., 2008).

Através da ingestão média de MS, em $\mathrm{kg} / \mathrm{kg}$ de PC metabólico (UTM/dia) dos animais canulados no rúmen, obteve-se a equação de regressão da ingestão, considerando o nível de suplementação $\mathrm{y}=0,045+0,020 \mathrm{x}$, onde $\mathrm{y}=$ ingestão de MS de pasto $\mathrm{kg} / \mathrm{kg}^{0,75}$ de $\mathrm{PC}$ e $\mathrm{x}=$ nível de suplementação. Após aplicar o nível de suplementação na equação, obteve-se: $\quad 0,045 ; \quad 0,055 ; \quad 0,065$; $0,075 \mathrm{~kg} / \mathrm{kg}^{0,75}$ de PC por dia para 0,0 ; 0,$5 ; 1,0 ; 1,5 \%$, respectivamente. A IMS total foi determinada a partir do somatório do consumo do pasto (somatório da extrusa e fezes) e do concentrado. A conversão alimentar foi determinada pela relação entre a quantidade de matéria seca consumida e o ganho de peso.

Os abates ocorreram quando os animais do grupo de $1,5 \%$ de suplementação atingiram PC médio de 23,10 $\pm 1,74 \mathrm{~kg}$, que foi concomitante com idade média de um ano. Os cabritos foram submetidos a jejum de sólidos e líquidos por 16 horas, para, em seguida, ser determinado o peso vivo de abate em jejum (PVAJ).

$\mathrm{O}$ abate iniciou com a insensibilização pelo método de concussão percurssivo não penetrativo, seguido de sangria, com corte da carótida e jugular, em atendimento a legislação vigente, 
Rev. Bras. Saúde Prod. Anim., Salvador, v.16, n.3, p.723-735 jul./set.., $2015 \quad \underline{\text { http://www.rbspa.ufba.br }}$

segundo instrução normativa $\mathrm{n}^{\circ} 3$, de 17 de janeiro de 2000, (BRASIL, 2000). Após a esfola e evisceração, foram retirados e pesados os componentes não integrantes da carcaça: sangue, cabeça, patas, pele, língua, coração, trato respiratório, esôfago, baço, fígado, rins, pâncreas, gordura omental, gordura mesentérica, gordura perirenal, trato gastrointestinal (TGI) cheio e vazio, bexiga cheia e vazia e trato reprodutivo (testículos e pênis). A partir daí, foi registrado o peso da carcaça quente (PCQ), rendimento em relação ao peso do corpo vazio (PCV) e das vísceras (sangue, língua, coração, esôfago, baço, fígado, pâncreas e TGI vazio). Esse último, para determinar seu rendimento, foi utilizado o somatório dos órgãos que a compõem pela razão do PVAJ multiplicado por 100 .

O PCV foi obtido a partir da equação: $\mathrm{PCV}=$ PVAJ - (conteúdo do TGI + bexiga), visando avaliar o rendimento verdadeiro $(\mathrm{RV})$, em que RV $(\%)=$ (PCQ)/PCV x 100.

As carcaças foram identificadas e resfriadas sem proteção plástica, à temperatura de 3 a $5^{\circ} \mathrm{C}$ por 24 horas, e penduradas pelo tendão calcâneo comum, distanciadas em $14 \mathrm{~cm}$. Ao final do resfriamento, as carcaças foram pesadas obtendo-se o peso da carcaça fria (PCF), a partir do qual foi estimada a perda de peso ocasionada pelo processo de resfriamento $(\mathrm{PR}=\mathrm{PCQ}-$ PCF/PCQ $x$ 100) e o rendimento da carcaça fria $(\mathrm{RCF}=\mathrm{PCF} / \mathrm{PVA} \times 100)$.

A carcaça foi dividida longitudinalmente, onde as meiacarcaças foram seccionadas em cinco regiões anatômicas: pescoço, paleta, costela, lombo e perna (CEZAR \& SOUZA et al., 2007). O peso individual de cada corte, composto pelos cortes efetuados na meia-carcaça esquerda e direita, foi registrado para cálculo de sua proporção em relação à soma das duas meias-carcaças, obtendo-se o rendimento comercial dos cortes.

$\mathrm{Na}$ porção dorsal do músculo Longissimus dorsi, na altura entre a $13^{\mathrm{a}}$ e $12^{\mathrm{a}}$ vértebra torácica, com o auxílio de um paquímetro, foram efetuadas mensurações da largura e profundidade máxima, para cálculo da área de olhode-lombo (AOL).

$\mathrm{O}$ delineamento estatístico utilizado foi o inteiramente casualizado, com quatro tratamentos e dez repetições, seguindo o modelo matemático $\mathrm{Yij}=\mu+\mathrm{ti}+\mathrm{eij}$, onde: $\mathrm{Yij}=$ valor observado na parcela que recebeu o tratamento i na repetição $\mathrm{j} ; \mu=$ média geral; ti $=$ efeito do tratamento $\mathrm{i}$; eij = erro aleatório. Os dados foram testados quanto à homogeneidade das variâncias pelo teste de Bartlett (PROC GLM); a normalidade dos erros, pelo teste de Shapiro-Wilk (PROC UNIVARIATE), pré-requisitos necessários para a análise de variância. $\mathrm{O}$ modelo utilizado para as análises de regressão linear foi $\mathrm{y}=\mathrm{a}+$ bX, o qual mostra o comportamento da variável dependente y em função da variável independente $\mathrm{x}$, utilizoando-se, para tal, o PROC REG. Para as análises de variância e correlação simples entre as variáveis estudadas, foi utilizado o pacote estatístico SAS (1999) e a correlação de Pearson, pelo procedimento CORR do programa SAS (1999).

\section{RESULTADOS E DISCUSSÃO}

O desempenho e as características de carcaça dos caprinos Canindé (Tabela 2) mostraram-se diferentes $(\mathrm{P}<0,001)$, verificando-se comportamento linear crescente nos consumos e ganhos de peso, rendimentos e área de olho-delombo em função dos níveis de suplementação. 
Tabela 2. Desempenho e características de carcaça de caprinos Canindé criados em sistema de pastejo na caatinga em função dos níveis de suplementação

\begin{tabular}{|c|c|c|c|c|c|c|c|}
\hline \multirow{2}{*}{ Variável } & \multicolumn{4}{|c|}{ Níveis de suplementação } & \multirow{2}{*}{$\mathrm{CV} \%$} & \multirow{2}{*}{ Equação de regressão } & \multirow{2}{*}{$\mathrm{R}^{2}$} \\
\hline & $0 \%$ & $0,5 \%$ & $1 \%$ & $1,5 \%$ & & & \\
\hline Consumo total de $\mathrm{MS}^{1,2}$ & 348,28 & 539,55 & 756,86 & 950,16 & 5,01 & $\hat{\mathrm{y}}=0,486+0,074 \mathrm{x}^{* *}$ & 0,96 \\
\hline Consumo total de $\mathrm{MS}^{1}(\% \mathrm{PV})$ & 3,43 & 3,84 & 3,99 & 3,83 & 1,73 & $\hat{y}=3,46+0,126 x^{* *}$ & 0,91 \\
\hline Consumo de forragem ${ }^{2}$ & 348,28 & 465,09 & 581,73 & 696,89 & 24,61 & $\hat{y}=348,63+232,4 x^{* *}$ & 0,99 \\
\hline Consumo de concentrado ${ }^{2}$ & 0 & 74,46 & 175,13 & 253,27 & 72,70 & $\hat{y}=-3,52+172,3 x^{* *}$ & 0,97 \\
\hline Ganho de peso total ${ }^{3}$ & $-0,35$ & 2,60 & 5,53 & 7,96 & 47,99 & $\hat{\mathrm{y}}=-3,008+2,779 \mathrm{x}^{* *}$ & 0,72 \\
\hline Ganho de peso diário (g/dia) & $-0,003$ & 0,019 & 0,044 & 0,066 & 46,06 & $\hat{\mathrm{y}}=-0,026+0,023 \mathrm{x} * *$ & 0,72 \\
\hline Conversão alimentar & 30,25 & 32,56 & 17,45 & 15,80 & 58,74 & $\hat{y}=32,93+11,90 x^{* *}$ & 0,23 \\
\hline Peso vivo ao abate ${ }^{3}$ & 14,81 & 18,67 & 21,59 & 23,10 & 9,39 & $\hat{y}=10,26+4,80 x * *$ & 0,75 \\
\hline Peso vivo ao abate em jejum ${ }^{3}$ & 13,66 & 17,16 & 19,86 & 21,24 & 9,56 & $\hat{\mathrm{y}}=11,72+2,51 \mathrm{x} * *$ & 0,74 \\
\hline Peso de corpo vazio ${ }^{3}$ & 11,02 & 11,96 & 14,82 & 16,33 & 9,46 & $\hat{y}=9,32+1,10 x * *$ & 0,80 \\
\hline Peso de carcaça quente ${ }^{3}$ & 4,92 & 6,43 & 8,19 & 8,93 & 9,60 & $\hat{\mathrm{y}}=4,88+0,13 \mathrm{x}^{* *}$ & 0,64 \\
\hline Rendimento de carcaça quente ${ }^{4}$ & 36,19 & 37,56 & 41,21 & 42,08 & 6,09 & $\hat{\mathrm{y}}=33,33+2,09 \mathrm{x} * *$ & 0,65 \\
\hline Peso de carcaça fria $^{3}$ & 4,61 & 6,14 & 7,84 & 8,62 & 9,66 & $\hat{y}=4,58+0,13 x * *$ & 0,65 \\
\hline Rendimento de carcaça fria $^{4}$ & 33,89 & 35,88 & 39,48 & 40,60 & 5,23 & $\hat{y}=33,201+0,236 x^{* *}$ & 0,61 \\
\hline Perda no resfriamento ${ }^{4}$ & 6,09 & 4,49 & 4,19 & 3,53 & 38,51 & $\hat{\mathrm{y}}=5,982-0,078 \mathrm{x} * *$ & 0,36 \\
\hline Rendimento verdadeiro ${ }^{4}$ & 50,31 & 52,92 & 55,13 & 55,28 & 3,63 & $\hat{y}=49,130+0,008 x * *$ & 0,38 \\
\hline Àrea de olho de lombo 5 & 3,76 & 5,09 & 6,64 & 6,98 & 23,2 & $\hat{\mathrm{y}}=3,70+0,781 \mathrm{x}^{* *}$ & 0,50 \\
\hline
\end{tabular}

$(\mathrm{CV})$; coeficiente de determinação $\left(\mathrm{R}^{2}\right)$; ** Significativo a $1 \%$ probabilidade. 
A ingestão total de matéria seca, forragem e concentrado e o ganho de peso médio (Tabela 2) apresentaram comportamento linear crescente com o aumento dos níveis de suplementação, maximizando o peso vivo de abate em jejum, peso de corpo vazio e os rendimentos da carcaça. Este efeito deve-se à rápida digestão dos carboidratos não fibrosos ingeridos pelos animais submetidos à adição da suplementação, que, por sua vez, são componentes de rápida fermentação (SANTOS, 2006), permanecendo menos tempo no ambiente ruminal, proporcionando maior consumo diário total de matéria seca.

Os ganhos totais de peso dos animais desse estudo (Tabela 2) variaram de 0,35 a 7,96, quando os níveis de suplementação foram de zero a $1,5 \%$, resultados esses que foram menores, porém próximos aos encontrados por Marques et al. (2014), ao estudarem caprinos nativos Moxotó suplementados na caatinga. As diferenças podem ser explicadas pelos diferentes genótipos, como nos valores de precipitação e, consequentemente, de disponibilidade de forragem para pastoreio.

O aumento do peso de corpo vazio observado neste estudo ocorreu em decorrência dos maiores consumos de forragem e de concentrado, associado à possibilidade do menor tamanho do trato gastrintestinal dos animais mantidos com os maiores níveis de suplementação.

Silva et al. (2014), avaliando características de carcaça de caprinos mestiços anglonubianose, Marques et al. (2014), as características de caprinos Moxotó, ambos os estudos em pastagem de caatinga, recebendo suplementação alimentar, encontraram valores médios de rendimentos de carcaça quente e fria, de 40,9 e $39,10 \%$; e 45,7 e $43,61 \%$, respectivamente. Valores esses que foram superiores aos obtidos, neste estudo, para as mesmas variáveis, 39,26 e $37,46 \%$, respectivamente. Assim como observado para os valores de ganho em peso, os índices de rendimento de carcaça refletem que os cabritos do presente estudo apresentaram um desempenho inferior a outros animais em condições de pastejo; é indispensável, portanto, considerar a influência do ano e das condições de pasto ao comparar estudos com animais.

A perda por resfriamento (PR) expressa a diferença de peso antes e após o resfriamento da carcaça, variando, principalmente, em função da quantidade de gordura de cobertura e da perda de umidade (CUNHA et al., 2008). A partir disso, verificou-se, neste estudo, variação de PR de 6,09 a 3,53\%, em função do aumento dos níveis de suplementação, sendo considerada levemente alta. Mattos et al. (2006) atribuem maiores valores de PR à pouca cobertura de gordura nesses animais, além de que a espécie caprina naturalmente apresenta reduzida deposição de gordura subcutânea em detrimento da maior deposição de gordura cavitária.

A área de olho-de-lombo (AOL) é considerada como sendo um indicador de musculosidade da carcaça, onde foi observado, neste estudo, um efeito linear crescente (Tabela 2), resultado esse que, segundo Pereira Filho et al. (2008), pode apresentar resposta direta ao crescimento animal, implicando em obtenção de maiores pesos de abate em jejum e de corpo vazio, refletindo em maior quantidade de músculo, representando, assim, AOL mais elevada.

Os rendimentos dos cortes comerciais (paleta, perna, pescoço, costela e lombo em $\mathrm{kg}$ ) e a porcentagem da paleta e do lombo em relação ao peso de carcaça fria (Tabela 3) apresentaram comportamento linear crescente $(\mathrm{P}<0,001)$ com $\mathrm{O}$ aumento dos níveis de suplementação, naturalmente em reflexo do efeito 
Rev. Bras. Saúde Prod. Anim., Salvador, v.16, n.3, p.723-735 jul./set.., $2015 \quad \underline{\text { http://www.rbspa.ufba.br }}$ ISSN 15199940

apresentado pelos pesos absolutos da carcaça fria, que, por sua vez, influenciaram os pesos dos cortes, quando expressos em $\mathrm{kg}$.

A participação dos cortes na carcaça permite uma avaliação qualitativa, pois deve apresentar a melhor proporção possível de cortes com maior conteúdo de tecidos comestíveis, especialmente músculos (YÁNEZ et al., 2006). A paleta e o lombo apresentaram variações decorrentes do ganho de peso dos animais, todavia, as proporções da perna, pescoço e costela mantiveram-se semelhantes. É provável que este fato implique em uma maior síntese $\mathrm{e}$ deposição de tecido muscular, com acréscimo do nível de suplementação.

Tabela 3. Rendimento dos cortes comerciais de caprinos Canindé criados em sistema de pastejo na caatinga em função dos níveis de suplementação

\begin{tabular}{|c|c|c|c|c|c|c|c|}
\hline \multirow{2}{*}{ Variável } & \multicolumn{4}{|c|}{ Níveis de suplementação } & \multirow[b]{2}{*}{$\mathrm{CV} \%$} & \multirow[b]{2}{*}{ Equação de regressão } & \multirow{2}{*}{$\mathrm{R}^{2}$} \\
\hline & 0,0 & 0,5 & 1,0 & 1,5 & & & \\
\hline Paleta $(\mathrm{kg})$ & 0,517 & 0,665 & 0,829 & 0,900 & 9,52 & $\hat{\mathrm{y}}=0,492+0,115 \mathrm{x} * *$ & 0,82 \\
\hline Perna $(\mathrm{kg})$ & 0,874 & 1,072 & 1,347 & 1,401 & 19,15 & $\hat{y}=1,047-0,333 x^{* *}$ & 0,48 \\
\hline Pescoço (kg) & 0,235 & 0,282 & 0,405 & 0,411 & 21,13 & $\hat{\mathrm{y}}=0,451+0,412 \mathrm{x} * *$ & 0,55 \\
\hline Costela (kg) & 0,523 & 0,720 & 0,942 & 1,100 & 17,80 & $\hat{\mathrm{y}}=0,503+0,02 \mathrm{x} * *$ & 0,54 \\
\hline Lombo (kg) & 0,186 & 0,291 & 0,380 & 0,435 & 16,27 & $\hat{\mathrm{y}}=0,182+0,008 \mathrm{x} * *$ & 0,76 \\
\hline Paleta (\% PCF) & 20,92 & 21,14 & 21,72 & 22,42 & 5,41 & $\hat{y}=23,01-0,45 x^{* *}$ & 0,20 \\
\hline Perna (\% PCF) & 32,66 & 34,32 & 34,78 & 37,24 & 16,05 & $\hat{y}=34,75$ & 0,09 \\
\hline Pescoço (\%PCF) & 9,21 & 9,48 & 10,16 & 10,36 & 16,23 & $\hat{y}=9,80$ & 0,11 \\
\hline Costela (\% PCF) & 22,75 & 23,24 & 24,06 & 25,05 & 15,74 & $\hat{\mathrm{y}}=23,77$ & 0,05 \\
\hline Lombo (\% PCF) & 7,98 & 9,49 & 9,75 & 10,11 & 14,37 & $\hat{y}=8,153+0,065 x * *$ & 0,27 \\
\hline
\end{tabular}

A soma do rendimento dos cortes de maior valor comercial em peso absoluto e em porcentagem de carcaça fria (perna, paleta e lombo) representou 1,$577 ; 2,028 ; 2,556$ e $1,736 \mathrm{~kg}$, e 61,56 ; 64,$95 ; 66,25$; sendo $69,77 \%$, para os níveis de $0 ; 0,5 ; 1$ e $1,5 \%$ de suplementação, respectivamente. Valores esses, inferiores aos observados por Silva et al. (2014), avaliando cabritos mestiços anglonubiano terminados em pastagem de caatinga recebendo suplementação alimentar, onde foram abatidos com peso médio de $20 \mathrm{~kg}$ de peso corporal, resultado que pode ser justificado pelo maior tamanho corporal dos mestiços em relação aos Canindé.
Como sugerido por Gökdal (2013), diferenças no rendimento da carcaça em caprinos podem ser atribuídas às diferenças da idade e das condições de criação, podendo, ainda, ser influenciadas pela variação do peso da cabeça (pela presença de chifres), peso da pele (presença e peso do pelo) e outras variáveis, como o método e prática de abate, em relação ao peso de carcaça quente ou fria, peso de corpo inteiro, peso do corpo vazio ou peso de abate.

Os componentes não integrantes da carcaça apresentaram comportamento linear crescente em função dos níveis de suplementação, exceto o baço, coração, esôfago e rendimento de vísceras (Tabela 4). 
Rev. Bras. Saúde Prod. Anim., Salvador, v.16, n.3, p.723-735 jul./set.., $2015 \quad \underline{\text { http://www.rbspa.ufba.br }}$ ISSN 15199940

Tabela 4. Componentes não integrantes da carcaça de caprinos da raça Canindé criados em sistema de pastejo na caatinga, em função dos níveis de suplementação

\begin{tabular}{|c|c|c|c|c|c|c|c|}
\hline \multirow{2}{*}{ Variável (kg) } & \multicolumn{4}{|c|}{ Níveis de Suplementação } & \multirow{2}{*}{$\mathrm{CV} \%$} & \multirow{2}{*}{ Equação de regressão } & \multirow{2}{*}{$\mathrm{R}^{2}$} \\
\hline & $0 \%$ & $0,5 \%$ & $1,0 \%$ & $1,5 \%$ & & & \\
\hline Sangue & 0,49 & 0,61 & 0,73 & 0,75 & 16,70 & $\hat{y}=0,763+0,02 x^{* *}$ & 0,53 \\
\hline Baço & 0,01 & 0,01 & 0,02 & 0,02 & 17,37 & $\hat{\mathrm{y}}=0,015$ & 0,60 \\
\hline Coração & 0,06 & 0,07 & 0,08 & 0,09 & 20,38 & $\hat{y}=0,075$ & 0,22 \\
\hline Esôfago & 0,03 & 0,03 & 0,03 & 0,04 & 13,93 & $\hat{y}=0,035$ & 0,36 \\
\hline Cabeça & 0,98 & 1,10 & 1,23 & 1,31 & 10,63 & $\hat{y}=0,905+0,053 x^{* *}$ & 0,63 \\
\hline Patas & 0,38 & 0,45 & 0,51 & 0,55 & 7,95 & $\hat{y}=0,294+0,090 x^{* *}$ & 0,76 \\
\hline Pele & 0,68 & 0,89 & 1,03 & 1,17 & 11,77 & $\hat{\mathrm{y}}=0,340+0,43 \mathrm{x}^{* *}$ & 0,74 \\
\hline Fígado & 0,23 & 0,27 & 0,32 & 0,37 & 12,45 & $\hat{y}=0,194+0,041 x^{* *}$ & 0,61 \\
\hline Rins & 0,05 & 0,05 & 0,06 & 0,06 & 9,12 & $\hat{\mathrm{y}}=0,044+0,006 \mathrm{x}^{* *}$ & 0,33 \\
\hline Aparelho Respiratório & 0,21 & 0,23 & 0,28 & 0,32 & 14,56 & $\hat{y}=0,062+0,004 x^{* *}$ & 0,56 \\
\hline Gordura Omental & 0,04 & 0,13 & 0,28 & 0,36 & 52,10 & $\hat{y}=-0,037+0,087 x^{* *}$ & 0,66 \\
\hline Gordura Mesentérica & 0,13 & 0,17 & 0,27 & 0,28 & 25,90 & $\hat{y}=0,054+0,063 x^{* *}$ & 0,61 \\
\hline Gordura Perirenal & 0,02 & 0,07 & 0,19 & 0,23 & 59,62 & $\hat{y}=-0,041+0,065 x^{* *}$ & 0,55 \\
\hline Trato gastrintestinal vazio & 1,07 & 1,19 & 1,34 & 1,47 & 11,75 & $\hat{\mathrm{y}}=0,822+0,141 \mathrm{x}^{* *}$ & 0,58 \\
\hline Vísceras & 2,26 & 2,60 & 3,00 & 3,26 & 9,55 & $\hat{y}=1,883+0,339 x^{* *}$ & 0,68 \\
\hline Rendimento Vísceras ${ }^{1}$ & 16,96 & 15,29 & 15,27 & 15,40 & 12,97 & $\hat{y}=15,73$ & 0,09 \\
\hline
\end{tabular}

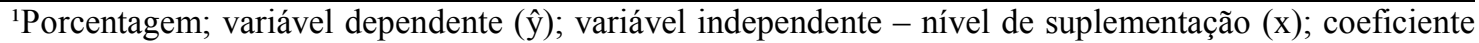
de variação $(\mathrm{CV})$ e coeficiente de determinação $\left(\mathrm{R}^{2}\right)$.

**Significativo a $1 \%$ probabilidade.

O efeito linear crescente da suplementação no peso dos órgãos pode estar relacionado à diferença no crescimento da carcaça em relação aos componentes não integrantes da carcaça (YÁÑEZ et al., 2006), parecendo refletir o crescimento do trato gastrintestinal no final da fase de cria em função do tipo de alimento (volumoso e concentrado) e o manejo alimentar, se estabilizando na fase adulta.

O fato do peso da cabeça e das patas apresentarem efeito linear crescente $(\mathrm{P}<0,001)$, em função dos níveis de suplementação, pode ser explicado pelo maior desenvolvimento dos animais, decorrente da maior disponibilidade de nutrientes nos maiores níveis suplementares. Além disso, Marques et al. (2008) afirmaram que o crescimento da cabeça apresenta desenvolvimento precoce, diminuindo sua proporção em relação ao peso vivo, sempre que o animal se desenvolve.

Oliveira et al. (2008) citam que a pele representa de 10 a $12 \%$ do valor do animal, explicando, de fato, que o crescimento ocorre de maneira proporcional e o maior peso da pele nos animais com o maior nível de suplementação.

Jenkins \& Leymaster (1993) afirmam que os órgãos essenciais aos processos vitais de respiração e do metabolismo possuem desenvolvimento maior ao nascimento, enquanto que aqueles associados à locomoção e ao armazenamento de nutrientes apresentam desenvolvimento mais tardio. Assim, os órgãos de crescimento precoce, como o fígado, $\mathrm{o}$ trato respiratório e os rins, que apresentam alta taxa metabólica, demonstram um comportamento linear crescente em função dos níveis de suplementação. 
A gordura é o componente não integrante da carcaça que apresenta maior variação em função do nível nutricional ingerido, pois o aumento da quantidade de gordura interna (omental, mesentérica e perirenal), que, nesse estudo, foi expressa pelo efeito linear crescente (Tabela 4), poderá, segundo Monte et al. (2007), implicar em uma maior habilidade fisiológica em depositar gordura intra-abdominal, constituindo-se, em um aspecto, reserva energética para $o$ animal durante $o$ período de seca, o que reduz a degradação de proteína muscular durante essa época do ano. Os resultados observados para os pesos de gordura omental, mesentérica e perirenal corroboram com os que foram obtidos por Mattos et al. (2006), que, ao avaliarem dois níveis suplementares em cabritos das raças Canindé e Moxotó, verificaram aumento no peso dessas variáveis. Além disso, caprinos apresentam uma tendência em depositar maior quantidade de gordura intraabdominal, quando comparada à deposição de gordura subcutânea, inter e intramuscular (COLOMER-ROCHER et al., 1992).

$\mathrm{O}$ peso do trato gastrintestinal vazio aumentou linearmente com o aumento do nível de suplementação, associado à provável ingestão de forragens com elevado nível de fibra (72\%) e de baixa digestibilidade (51\%), aumentando, possivelmente, o tempo de retenção do alimento no rúmen.

Mattos et al. (2006) sugerem que raças de menor porte, como a Canindé, sejam abatidas a pesos menores que raças de maior tamanho, a fim de evitar a necessidade de retirada da gordura cavitária em excesso, o que desvaloriza o produto no mercado consumidor. Pode-se dizer, com base nos resultados obtidos (Tabela 4), que o nordeste possui, para suas condições de semiárido, um material genético de qualidade para a produção de carne com baixo teor de gordura total (somatório médio de gordura omental, mesentérica e perirenal: $0,540 \mathrm{~g}$ ), desde que se adote um nível mínimo de tecnologia, como a utilização de suplementação concentrada nos períodos de escassez alimentar.

A utilização de vísceras comestíveis no preparo de pratos como a "buchada" pode ser uma alternativa econômica, pois agrega valor e aumenta a lucratividade da produção, gerando renda adicional ao produtor (SANTOS et al., 2005). Sendo assim, a adição da suplementação concentrada favoreceu o aumento linear no peso de vísceras (Tabela 4), podendo possibilitar a obtenção de maior renda na comercialização desses animais.

$\mathrm{O}$ peso ao abate de aproximadamente $23 \mathrm{~kg}$, nos animais submetidos ao maior nível de suplementação concentrada em condições de pastejo, no presente estudo, foi atingido quando eles apresentavam idade aproximada de um ano.

A suplementação concentrada influencia o desempenho dos animais promovendo maior aporte de nutrientes, sendo que os níveis de 1 e 1,5\% proporcionam melhores rendimentos e quilos de carcaça fria para comercialização, possibilitando, ainda, maiores pesos dos componentes não constituintes da carcaça de caprinos Canindé criados em pastejo na caatinga.

\section{REFERÊNCIAS}

ASSOCIATION OF OFFICIAL ANALYTICAL CHEMISTRY AOAC. Official Methods of Analysis. 15.ed. Arlington: AOAC International, 1990. $1117 \mathrm{p}$. 
Rev. Bras. Saúde Prod. Anim., Salvador, v.16, n.3, p.723-735 jul./set.., $2015 \quad \underline{\text { http://www.rbspa.ufba.br }}$ ISSN 15199940

BRASIL. Ministério da Agricultura. Instrução normativa $\mathrm{n}^{0} 3$ de 7 de Janeiro de 2000. Regulamento técnico de métodos de insensibilização para o abate humanitário de animais de açougue. S.D.A./M.A.A. Diário Oficial da União, Brasília, p.14-16, 24 de Janeiro de 2000, Seção I. Disponível em:

$<$ www.agricultura.gov.br/das/dipoa/Ane xo $\% 20$ Abate.htm $>$. Acesso em. 10 Nov. 2010 .

CARVALHO JUNIOR, A.M.; PEREIRA FILHO, J.M.; SILVA, R.M.; CEZAR, M.F.; SILVA, A.M.A.;

SILVA, A.L.N. Componentes nãocarcaça de caprinos F1 Boer $\times$ SRD terminados em pastagem nativa.

Revista Brasileira de Zootecnia, v.38, n.7, p.1301-1308, 2009.

CASALI, A.O.; DETMAN, E.;

VALADARES FILHO, S.C.; PEREIRA, J.C.; HENQIQUES, L.T.; FREITAS, S.G.; PAULINO, M.F. Influência do tempo de incubação e do tamanho de partículas sobre os teores de compostos indigestíveis em alimentos e fezes bovinas obtidos por procedimentos in situ. Revista

Brasileira de Zootecnia, v.37, n.2, p.335-342, 2008.

CEZAR, M.F.; SOUSA, W.H. Carcaças ovinas e caprinas: obtenção, avaliação e classificação. Uberaba: Agropecuária Tropical, 2007. 147p.

COLOMER-ROCHER, F.; KIRTON, A.H.; MERCER, G.J.K. Carcass composition of New Zealand Saanen goats slaughtered at different weights. Small Ruminant Research, v.7, n.2, p.161- 173, 1992.
CUNHA, M.G.G.; CARVALHO, F.F.R.; GONZAGA NETO, S.; CEZAR, M.H.Características quantitativas de carcaça de ovinos Santa Inês confinados alimentados com rações contendo diferentes níveis de caroço de algodão integral. Revista Brasileira de Zootecnia, v.37, n.6, p.1112-1120, 2008.

DE VRIES, D.M. Methoden van botanisch grasland onder zocken grasland waardering. Lecture Given at Wageningen, The Netherlands, 25 May, (Mimco), 1958.

GOKDAL, Ö. Growth, slaughter and carcass characteristics of Alpine $\times$ Hair goat, Saanen $\times$ Hair goat and Hair goat male kids fed with concentrate in addition to grazing on rangeland. Small Ruminant Research, v.109, n.2-3, p.69-75, 2013.

JENKINS, T.G.; LEYMASTER, K.A. Estimates of maturing rates and masses at maturity for body components of sheep. Journal of Animal Science, v.71, p.2952-2957, 1993.

LISBOA, A.C.C.; FURTADO, D.A.; MEDEIROS, A.N.; COSTA, R.G.; QUEIROGA, R.C.R.E.; BARRETO, L.M.G.; PAULO, J.L.A. Avaliação da qualidade da carne de cabritos nativos terminados com dietas contendo feno de Maniçoba. Revista Brasileira de Saúde e Produção Animal [online], v.11, n.4, p.1046-1055, 2010.

MARQUES, A.V.M.S.; COSTA, R.G.; SILVA, A.M.A.; PEREIRA FILHO, J.M.; LIRA FILHO, G.E.; SANTOS, N.M.Feno de flor de seda (Calotropis procera $\mathrm{SW}$ ) em dietas de cordeiros Santa Inês: Biometria e rendimento dos componentes não-constituintes da carcaça. Revista Brasileira de Ciências Agrárias, v.3, n.1, p.85-89, 2008. 
Rev. Bras. Saúde Prod. Anim., Salvador, v.16, n.3, p.723-735 jul./set.., $2015 \quad \underline{\text { http://www.rbspa.ufba.br }}$ ISSN 15199940

MARQUES, A.A.T.; MEDEIROS, A.N.; COSTA, R.G.; CARVALHO, F.F.R.; ARAÚJO, M.J. TORREÃO, J.N.C. Performance and carcass traits of Moxotó growing goats supplemented on native pasture under semiarid conditions.

Revista Brasileira de Zootecnia, v.43, n.3, p.151-159, 2014.

MATTOS, C.W.; CARVALHO, F.F.R.; DUTRA JÚNIOR, W.M.; VÉRAS, A.S.C.; BATISTA, A.M.V.; ALVES, K.S.; RIBEIRO, V.L.; SILVA, M.J.M.S.; MEDEIROS, G.R. Características de carcaça e dos componentes não-carcaça de cabritos Moxotó e Canindé submetidos a dois níveis de alimentação1. Revista Brasileira de Zootecnia, v.35, n.5, p.2125-2134, 2006.

MONTE, A.L. de S.; SELAIVEVILLARROEL, A.B.; OLIVEIRA, A.N. de; PEREZ, J.R.O; ZAPATA, J.F.F.; RAFAEL ELIAS RAMOS, R.E. Rendimento das vísceras de cabritos mestiços Anglo x SRD e Boer x SRD.

Ciência e Agrotecnologia, v.31, n.1, p.223-227, 2007

NATIONAL RESEARCH COUNCIL NRC. Nutrient requirements of small ruminants: sheep, goats, cervids, and new world camelids. Washington, D.C.: National Academy Press, 2007. 362p

OLIVEIRA, A.M.; SELAIVEVILLARROEL, A.B.; MONTE, A.L.S.; COSTA, R.G.; COSTA, L.B.A.Características da carcaça de caprinos mestiços Anglo-Nubiano, Boer e sem padrão racial definido. Ciência Rural, v.38, n.4, p.1073-1077, 2008.

PEREIRA FILHO, J.M.; RESENDE, K.T.; TEIXEIRA, I.A.M.A.

Características da carcaça e alometria dos tecidos de cabritos F1 Boer $\times$ Saanen1.

Revista Brasileira de Zootecnia, v.37, n.5, p.905-912, 2008.
SANTOS, N.M.; COSTA, R.G; MEDEIROS, A.N; MADRUGA, M.S.; GONZAGA NETO, S.Caracterização dos componentes comestíveis não constituintes da carcaça de caprinos e ovinos. Agropecuária Técnica, v.26, n.2, p.77-85, 2005.

SANTOS, J.E.P. Distúrbios metabólicos. Nutrição de Ruminantes. 1.ed. Jaboticabal: Funep, 2006583 p.

SANTOS, G.R.A.; BATISTA, A.M.V.; GUIM, A.; SANTOS, V.F.; SILVA, M.J.A.; PEREIRA, V.L.A. Determinação da composição botânica da dieta de ovinos em pastejo na Caatinga. Revista Brasileira de Zootecnia, v.37, n.10, p.1876-1883, 2008.

STATISTICAL ANALYSIS SYSTEM SAS. SAS User's guide: Statistics. Version 6.12. Cary, 1999. 956p.

SILVA SOBRINHO, A.G. SILVA, A.M.A. Produção Nacional da Carne.

Revista nacional da Carne, v.24, n. 285, p.32-44, 2000.

SILVA, D.C.; GUIM, A.; SANTOS, G.R.A.; MESQUITA, F.L.T.; MORAIS, N.A.P.; URBANO, S.A.; MOREIRA FILHO, M.A.; LAFAYETTE, E.A. Níveis de Suplementação sobre as características quantitativas da carcaça e composição tecidual do pernil de caprinos mestiços terminados na caatinga. Revista Brasileira de Saúde e Produção Animal, v.15, n.3, p.705-716, 2014.

SNIFFEN, C.J.; O'CONNOR, J.D.; VAN SOEST, P.J.; FOX, D.G; RUSSELL, J.B. A net carbohydrate and protein system for evaluating cattle diets: II. Carbohydrate and protein availability. Journal of Animal Science, v.70, n.11, p.35623577, 1992. 
SOUZA, A.P.; MEDEIROS, A.N.;

CARVALHO, F.F.R.; COSTA, R.G.;

RIBEIRO, L.P.S.; BEZERRA, A.B.;

BRANCO, G.L.C.; SILVA JR., C.G.

Energy requirements for maintenance and

growth of Canindé goat kids. Small

Ruminant Research, v.121, p.255-261, 2014.

TILLEY, J.M.; TERRY, R.A. A two stage technique for the in vitro digestion of forage crops. Journal British

Grassland Society, v.18, n.1,p.104111, 1963.

VAN SOEST, P.J.; ROBERTSON, J.B. Analysis of forages and fibrous foods. 1.ed. Itheca, NY: Cornell University. 1985.202p.

YÁÑEZ, E.A.; RESENDE, K.T. de; FERREIRA, A.C.D.; PEREIRA FILHO, J.M.; SILVA SOBRINHO, A.G. da; TEIXEIRA, I.A.M. de A.; MEDEIROS, A.N. de. Restrição alimentar em caprinos: rendimento, cortes comerciais e composição da carcaça. Revista Brasileira de Zootecnia, v. 35, n. 5, p. 2093-2100, 2006.

Data de recebimento: $14 / 01 / 2015$

Data de aprovação: 03/08/2015 